\title{
Influence of the flanges width and thickness on the shear strength of reinforced concrete beams with T-shaped cross section
}

\author{
Alberto Ayensa ${ }^{\mathrm{a}}$, Eva Oller ${ }^{\mathrm{b}}$, Beatriz Beltrán ${ }^{\mathrm{c}}$, Elena Ibarz $^{\mathrm{c}}$, Antonio Marí ${ }^{\mathrm{b}}$, Luis Gracia ${ }^{\mathrm{c}, *}$ \\ ${ }^{a}$ Architecture School, San Jorge University, 50830 Villanueva de Gállego, Zaragoza, Spain \\ ${ }^{\mathrm{b}}$ Department of Civil and Environmental Engineering, Polytechnic University of Catalonia, Campus Nord UPC, Building C-1, Jordi Girona, 1-3, 08034 Barcelona, Spain \\ ${ }^{\mathrm{c}}$ Department of Mechanical Engineering, University of Zaragoza, María de Luna 3, 50018 Zaragoza, Spain
}

\section{A R T I C L E I N F O}

\section{Keywords:}

Shear strength

T beams

Shear tests

Flanges

Effective width

Reinforced concrete

\begin{abstract}
A B S T R A C T
Shear design of reinforced concrete beams with T section considers only the contribution of the web, mainly provided by aggregate interlock. However, as the load increases and large web crack openings take place, aggregate interlock reduces and shear stresses tend to concentrate near the neutral axis, usually located in the flanges of $\mathrm{T}$ beams, whose contribution to shear strength may be not negligible, as it has been experimentally observed. Thus, the contribution of flanges may drive to considerable cost savings in new structures and may become decisive when evaluating the shear capacity of existing structures. To quantify such contribution, a nonlinear 3D-FEA model has been developed and calibrated with the results of shear tests performed on RC Tbeams by the authors. Once adjusted, the model has been used to analyze the shear response of beams with different geometry and longitudinal reinforcement, usual in practice. It has been found that, up to certain limits, the contribution of the flanges to the shear strength increases as the amount of longitudinal reinforcement decreases, as the flanges width increases and as the flange thickness increases. The maximum contribution of flanges found in the present study is $31.3 \%$ of the total shear resisted. Furthermore, the numerical model has been used to visualize and quantify aspects that are not easy to obtain experimentally, such as the distribution of the shear stresses between the web and the flanges. The present study will contribute to derive a design expression for the shear effective flanges width of $\mathrm{T}$ beams.
\end{abstract}

\section{Introduction}

Shear strength of reinforced concrete members is difficult to predict due to the complexity of the phenomena involved, such as the cracking induced anisotropy, the relevance of the multi-axial stress states generated, the interaction between concrete and reinforcement and the size effect associated to softening in compression or in tension. A large number of experimental and theoretical studies have been carried out along many years, resulting in considerably advances in the understanding of the shear resisting mechanism. Consequently, empirical and rational models capable to capture the experimental behavior have been developed [1-11], some of which are being incorporated in design and assessment concrete codes [12-14], even though most of them have been derived exclusively for members with a rectangular cross section.

Members with T, I or box sections are very usual in current construction of buildings and bridge decks due to their high flexural strength/weight ratio. Usually, current codes consider that bending is resisted by the couple of forces "C-T", being " $\mathrm{C}$ " the compression at the concrete head and " $\mathrm{T}$ " the tension at the longitudinal reinforcement, while shear is assumed to be taken by the web, by means of a truss mechanism. Therefore, no contribution of the flanges to the shear strength is considered, which is assumed to be totally resisted by the web, through aggregate interlock along the shear cracks.

However, experimental studies [15-22] show that the shear strength of slender reinforced concrete (RC) beams and slabs with a Tshaped section is higher than that of beams with equal height, web width and reinforcements amounts. As a matter of example, Fig. 1 shows that beams with $300 \mathrm{~mm}$ or wider flanges had about $25 \%$ greater ultimate strength than the rectangular beams [23]. Furthermore, the contribution of the flanges to the shear strength has been recognized and incorporated in some theoretical models, such as those presented in references [5,24-34].

According to the results of the above mentioned experimental and theoretical research works, it can be stated that a non-negligible contribution of the compression flange to the shear strength of beams with $\mathrm{T}$-shaped sections exists, that is being ignored in the shear provisions of

\footnotetext{
* Corresponding author at: Engineering and Architecture School, University of Zaragoza, María de Luna, 3, 50018 Zaragoza, Spain.

E-mail address: lugravi@unizar.es (L. Gracia).
} 


$\begin{array}{ll}\text { Nomenclature } \\ \mathrm{b}_{\mathrm{w}} \quad \text { web width } \\ \mathrm{b}_{\mathrm{f}} \quad \text { flange width } \\ \mathrm{b}_{\mathrm{v}} & \text { shear effective flange width } \\ \mathrm{h} & \text { beam depth } \\ \mathrm{h}_{\mathrm{f}} & \text { flange thickness } \\ \mathrm{d} & \text { beam effective depth } \\ \phi & \text { diameter of reinforcement bars } \\ \mathrm{f}_{\mathrm{ym}} & \text { steel yield strength } \\ \mathrm{f}_{\mathrm{um}} & \text { steel ultimate strength } \\ \varepsilon_{\mathrm{y}} & \text { steel yield strain }\end{array}$

$\varepsilon_{\mathrm{u}} \quad$ steel ultimate strain

$\mathrm{E}_{\mathrm{s}} \quad$ steel Young's modulus

$\mathrm{f}_{\mathrm{cm}, 28 \mathrm{~d}}$ concrete mean compressive strength at 28 days,

$\mathrm{f}_{\mathrm{cm} \text {,test }} \quad$ concrete mean compressive strength in experimental tests

$\mathrm{f}_{\mathrm{ctm} \text {,test }}$ concrete mean tensile strength in experimental tests

$\mathrm{E}_{\mathrm{cm} \text {,test }}$ concrete secant modulus in experimental tests

$\theta_{\text {web }} \quad$ web cracking angle

$\theta_{\text {flange }} \quad$ flange cracking angle

$\mathrm{V}_{\mathrm{u}} \quad$ maximum shear resisted

$\mathrm{V}_{\mathrm{u} \text {,test }} \quad$ maximum shear resisted in experimental tests

$\mathrm{V}_{\mathrm{c}} \quad$ concrete shear resisted current codes for design. To neglect such contribution in the design is a conservative solution, generally accepted, even though it is not accurate. However, the assessment of existing structures is nowadays very important due to the increasing number of infrastructures in service that need to be correctly evaluated. An excessively conservative design method, when applied to the evaluation of existing structures, may consider them non-acceptable, as it would be the case of many bridges currently in service, which show a satisfactory structural performance. Therefore, an accurate assessment of existing bridges and other transportation infrastructures, which are often being built with T-shaped cross section members, requires a realistic evaluation of the structure strength by means of models that take into account the flanges contribution.

In Fig. 1, it can be observed that for beams with constant web width $\left(b_{w}\right)$, the bigger the flange width $\left(b_{f}\right)$, the higher the shear resisted $\left(V_{u}\right)$ which may increase up to $25 \%$ with respect to the rectangular beam $\left(b=b_{w}\right)$, even though after a certain ratio $b / b_{w}, V_{u}$ remains constant. Similarly, for given web and flange widths, the thicker is the flange, the higher is the shear strength.

Such fact may be explained because the shear stresses transferred by aggregate interlock, inversely depend on the cracks opening, so that near Ultimate Limit State (ULS) shear transfer by aggregate interlock is only possible near the crack tip. Therefore, a relevant part of the shear stresses concentrates around the neutral axis, which in $\mathrm{T}$ beams is usually located in the flanges. Such stresses extend inside the flanges diminishing its intensity with the distance to the web, as theoretically obtained by Ribas and Cladera [31], Celada [32], Cladera et al. [33], after the model developed by Bairán and Marí [29], using a sectional model (Fig. 2). For this reason, after a certain value of the flanges width, no increment of shear strength is observed. On the other hand, in a thicker flange more shear stresses can be allocated and, therefore, a higher shear force may be resisted. However, this increment is

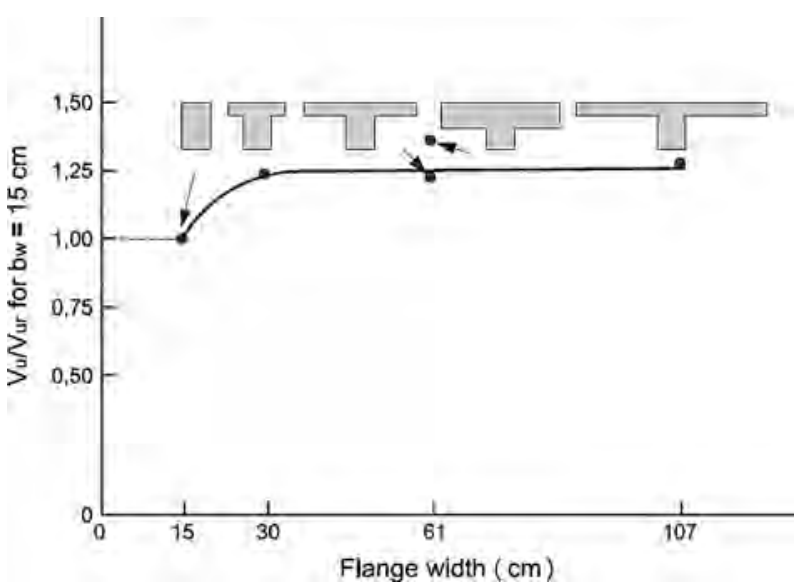

Fig. 1. Effects of flanges on shear strength in beams with T-shaped cross section $[16,17]$. progressively diminishing as the flange depth $h_{f}$, increases, since the shear stresses decrease with the distance to the neutral axis, due to the increment of the cracks width.

The fact that most shear stresses at high loading levels concentrate around the neutral axis, makes that a relevant part of them are located in the uncracked compressed concrete zone, where compressive normal stresses due to bending enhance the capacity of this region to resist shear. Furthermore, transverse reinforcement is usually placed in the flanges, to resist the shear lag effect and the transversal bending (Fig. 3). Such reinforcement confines the concrete in the transverse direction, thus incrementing the shear capacity of the compressed concrete zone of $\mathrm{T}$ beams.

Even though numerical models such as those based on non-linear 3D-Finite element analysis [35-37], may reproduce such complex phenomena, equations to take them into account in a simple but accurate way are necessary for a rational and safe design and assessment in engineering practice. For this purpose, the "shear effective flanges width" concept was developed, defined as a flange width that, assuming a constant shear stresses distribution in the transverse direction, would provide the same shear force in the flanges than the actual shear stresses distribution (Fig. 4).

Such concept was adopted by Placas et al. [18], Zararis et al. [28], Wolf and Frosch [30], Ribas and Cladera [31] and Cladera et al. [33] and $\mathrm{Li}$ et al [34], who incorporated it into their respective shear strength models. Predictions made by Cladera et al. [33] of the results of shear tests on T-shaped cross section beams, indicated that accounting for the effective shear width provides less conservative and disperse results with respect to the experimental values of ultimate shear. However, the scatter obtained when predicting the shear strength of $\mathrm{T}$ beams was much higher than when predicting the shear strength of rectangular beams. This indicated that, even though the effective shear width is a useful concept, its formulation requires a deeper study to capture the influence of the parameters involved and to improve the accuracy of the shear strength predictions. In fact, the expressions adopted up to now for the shear effective flanges width do not take into account the confinement effects of the flanges or the 3D flow of forces from the web to the flanges (shear lag effect), which need to be captured by 3D finite element analyses.

In this paper, numerical studies of reinforced concrete beams with $\mathrm{T}$-shaped sections failing in shear are performed by means of a nonlinear three-dimensional finite element analysis, aiming to study the influence of several design variables on the contribution of the flanges to the shear strength. For this purpose, Program ABAQUS version 6.14 [38], capable to capture the complex phenomena that governs the shear response of $T$ beams, has been used. First, the model parameters are adjusted to fit the global results of several shear tests performed by the authors on T-beams $[21,22]$. Then, comparisons of crack patterns and reinforcement strains are made to confirm the adequacy of the model to be used as a virtual laboratory. Once calibrated, the numerical model has been used to simulate shear tests on beams with different crosssection dimensions and reinforcement amounts. The results of the 

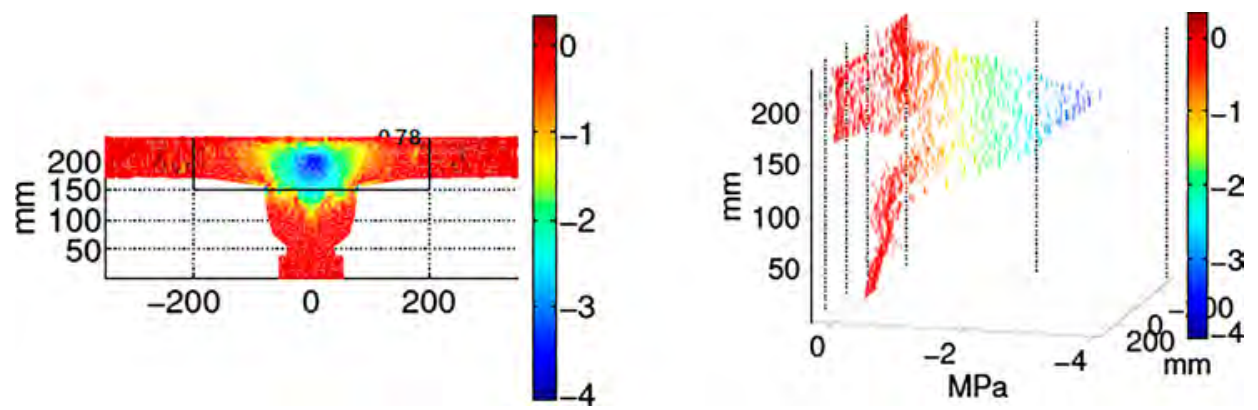

Fig. 2. Distribution of shear stresses in a beam with a T-shaped cross section [31].

numerical analyses have provided information about the structural response not easy to measure experimentally, such as the distribution of the shear stresses between the web and the flanges, very valuable for the quantification of the contribution of the web and the flanges on beams with different cross section geometry and longitudinal reinforcement. The results obtained in these studies as well as those of ongoing research studies to capture the influence of the transverse reinforcement and different combinations of $b_{f}, b_{w}, h_{f}$ and $d$, will be used to derive design equations for the effective shear width.

\section{Materials and methods}

\subsection{Description of the tested beams}

Two full-scale RC ( $M$ and $H$ ), with a T-shaped cross-section were monotonically tested under a point load up to failure, performing two tests on each beam. The beams were $5800 \mathrm{~mm}$ long with total height $550 \mathrm{~mm}$, web width $200 \mathrm{~mm}$, flanges width $600 \mathrm{~mm}$ and flanges depth $150 \mathrm{~mm}$, as shown in Fig. 5. Beams $\mathrm{M}$ and $\mathrm{H}$ had different bottom longitudinal reinforcement, consisting of two layers of $4 \phi 16$ for beams (M) and two layers of $2 \phi 16$ and $2 \phi 20$ for beams $(\mathrm{H})$. The top longitudinal reinforcement consisted of $4 \$ 12$. The web shear reinforcement consisted of $6 \mathrm{~mm}$ diameter stirrups spaced at $240 \mathrm{~mm}$ along the shear span, and $140 \mathrm{~mm}$ along the rest of the beam. The same spacing was used for the $8 \mathrm{~mm}$ diameter flange stirrups. Concrete cover was $20 \mathrm{~mm}$.

Two tests (denoted as a and b, respectively) were carried out in each beam with a span of $3300 \mathrm{~mm}$ and a shear span of $1480 \mathrm{~mm}$, which corresponds to three times the effective depth (Fig. 5). Once the beam failed by one end, the supports were moved to the other end of the beam using a symmetrical configuration for the next test, placing the

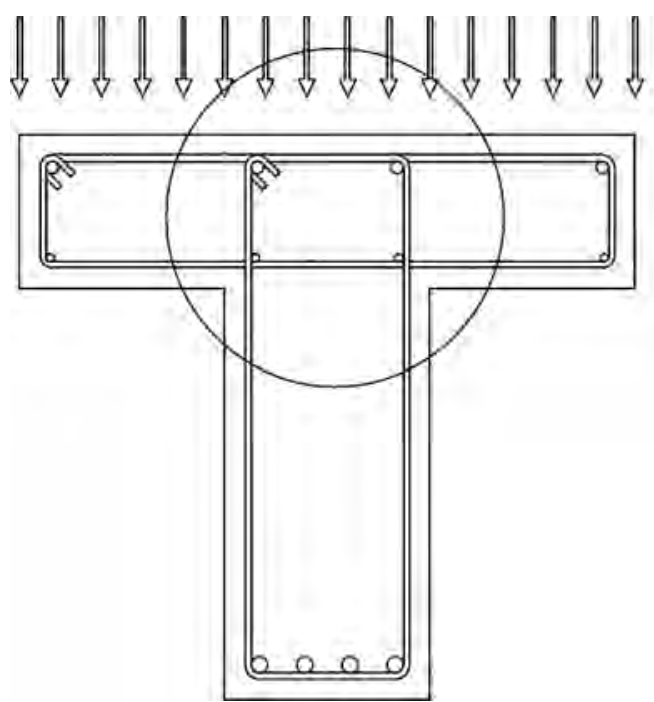

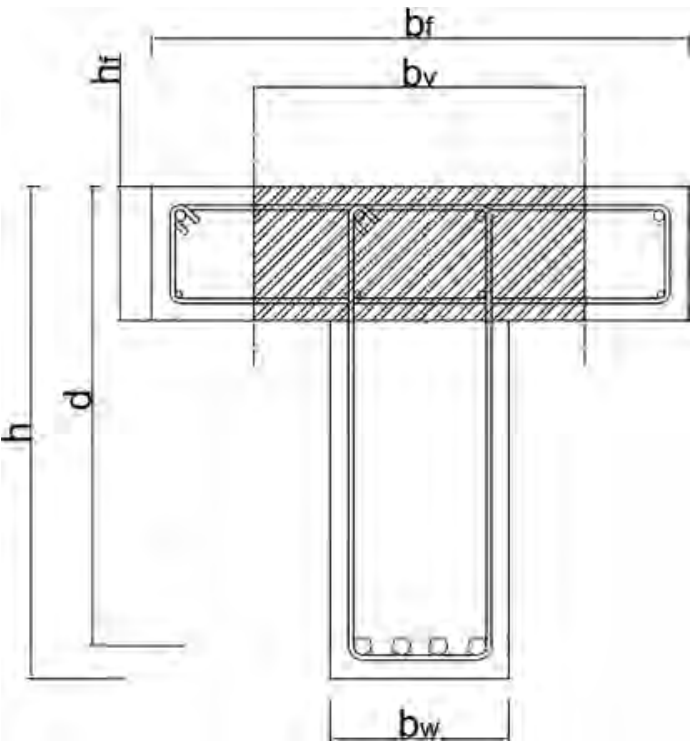

Fig. 4. "Shear effective flanges width" concept.

damaged part of the beam due to the first test just after the support.

All internal steel reinforcement had nominal yield strength of $500 \mathrm{~N} / \mathrm{mm}^{2}$. Tensile tests were performed for the different bar diameters employed. Results are summarized in Table 1.

Table 2 gives the concrete properties, the ultimate shear force and the critical shear crack inclination in the web and in the flange for each test. The ultimate shear force measured was much higher than the

Fig. 3. Confinement effects of the concrete web due to the transverse reinforcement forces. 


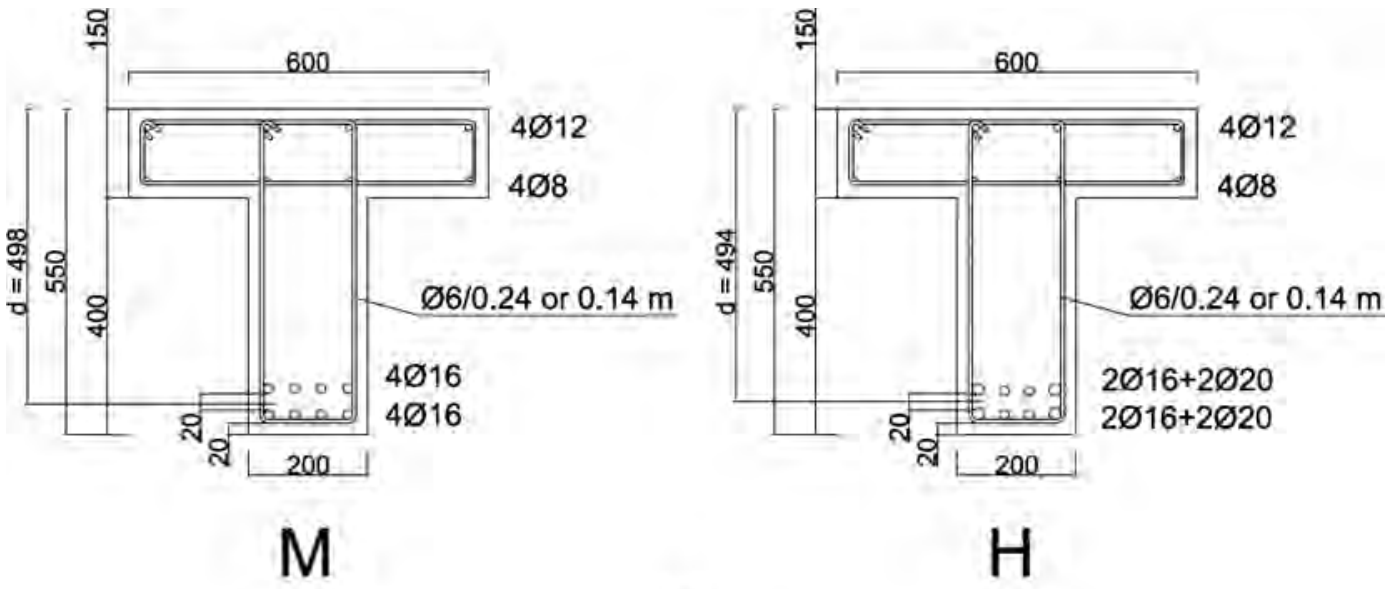

(a)

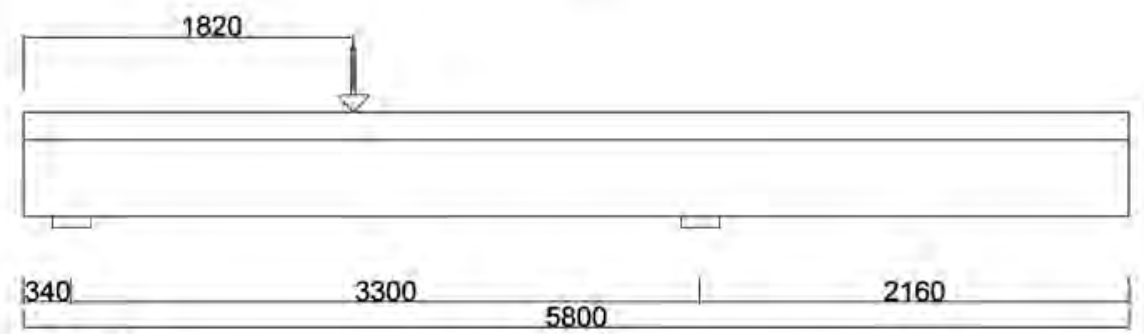

Test 1

1820

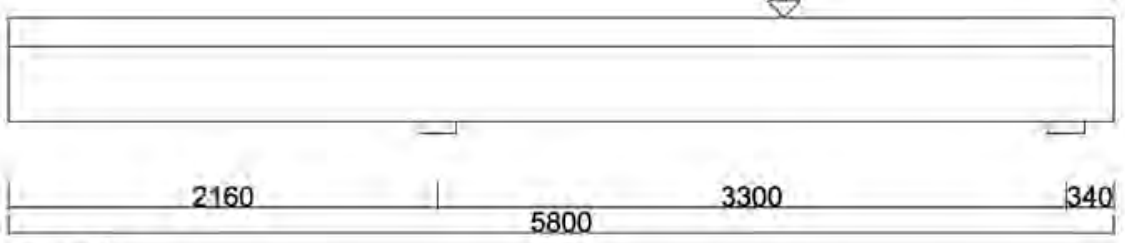

Test 2

(b)

Fig. 5. Tested beams geometry and shear test setup: (a) Transverse cross section of the tested beams; (b) longitudinal geometry and structural scheme.

Table 1

Summary of the internal steel properties.

\begin{tabular}{llllll}
\hline$\phi$ & $\begin{array}{l}\mathrm{f}_{\mathrm{ym}} \\
\left(\mathrm{N} / \mathrm{mm}^{2}\right)\end{array}$ & $\begin{array}{l}\mathrm{f}_{\mathrm{um}} \\
\left(\mathrm{N} / \mathrm{mm}^{2}\right)\end{array}$ & $\varepsilon_{\mathrm{u}}$ & $\varepsilon_{\mathrm{y}}$ & $\begin{array}{l}\mathrm{E}_{\mathrm{s}} \\
\left(\mathrm{N} / \mathrm{mm}^{2}\right)\end{array}$ \\
\hline 6 & 645.73 & 767.91 & 0.1444 & 0.0034 & 189,956 \\
8 & 642.26 & 765.65 & 0.1316 & 0.0069 & 204,750 \\
12 & 590.40 & 690.45 & 0.1680 & 0.0043 & 219,270 \\
16 & 572.24 & 685.27 & 0.1357 & 0.0029 & 196,121 \\
20 & 603.65 & 652.48 & 0.1262 & 0.0034 & 175,084 \\
\hline
\end{tabular}

predictions according to the existing codes (Eurocode 2 [12], Spanish Concrete Code EHE-08 [39]), considering only the web contribution, showing that a high contribution of the flanges to the shear resistance took place. As observed, an increase in the longitudinal reinforcement ratio of $29.7 \%$ resulted in an increment of just a $6 \%$ of the ultimate shear force. Both beams failed in an almost identical manner, with a critical shear crack involving two branches. The first branch, located in the web, was typically found to be steeper than the second branch which developed in the flange (see Table 2). Failure occurs with the formation of the second branch (Fig. 6).

Table 2

Concrete properties, ultimate shear force, critical shear crack inclination in the web and in the flange.

\begin{tabular}{|c|c|c|c|c|c|c|c|c|c|}
\hline Test & Casting Data & Test Data & $\begin{array}{l}\mathrm{f}_{\mathrm{cm}, 28 \mathrm{~d}} \\
\left(\mathrm{~N} / \mathrm{mm}^{2}\right)\end{array}$ & $\begin{array}{l}\mathrm{f}_{\mathrm{cm}, \text { test }} \\
\left(\mathrm{N} / \mathrm{mm}^{2}\right)\end{array}$ & $\begin{array}{l}\mathrm{f}_{\mathrm{ctm}, \text { test }} \\
\left(\mathrm{N} / \mathrm{mm}^{2}\right)\end{array}$ & $\begin{array}{l}\mathrm{E}_{\mathrm{cm}, \text { test }} \\
\left(\mathrm{N} / \mathrm{mm}^{2}\right)\end{array}$ & $\begin{array}{l}V_{u, t e s t} \\
(\mathrm{kN})\end{array}$ & $\begin{array}{l}\theta_{\text {web }} \\
\left(^{\circ}\right)\end{array}$ & $\begin{array}{l}\theta_{\text {flange }} \\
\left({ }^{\circ}\right)\end{array}$ \\
\hline $\mathrm{M}-\mathrm{a}$ & $11 / 06 / 28$ & $11 / 09 / 29$ & 32.9 & 40.2 & 3.7 & 31,632 & 299.9 & 27.5 & 9.0 \\
\hline M-b & $11 / 06 / 28$ & $11 / 10 / 04$ & 32.9 & 40.2 & 3.7 & 31,632 & 309.6 & 37.5 & 10.5 \\
\hline $\mathrm{H}-\mathrm{a}$ & $11 / 07 / 01$ & $11 / 09 / 20$ & 38.4 & 42.6 & 3.8 & 33,060 & 326.6 & 29.0 & 7.0 \\
\hline $\mathrm{H}-\mathrm{b}$ & $11 / 07 / 01$ & $11 / 09 / 27$ & 38.4 & 42.6 & 3.8 & 33,060 & 319.7 & 28.0 & 9.5 \\
\hline
\end{tabular}




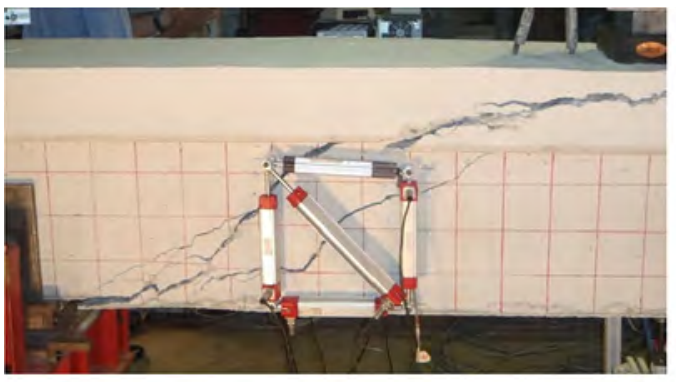

(a)

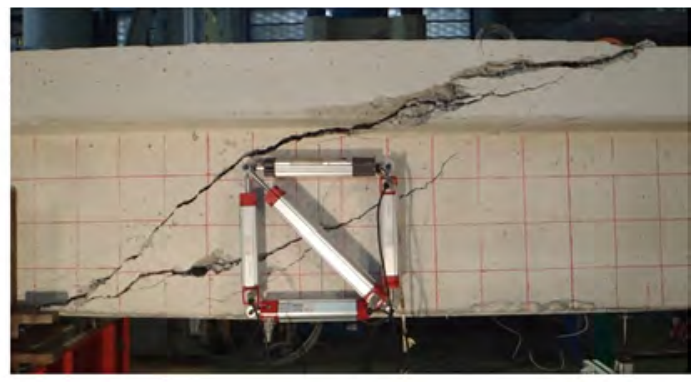

(b)

Fig. 6. Experimental testing: (a) Failure of beam M; (b) Failure of beam H.

\subsection{Description of finite element model and calibration with the experimental results}

The finite element model that represents the reinforced concrete beam is shown in Fig. 7. The 8-node linear brick element "C3D8R" of Abaqus and $15 \mathrm{~mm}$ size, with reduced integration and hourglass control, is used to create the mesh of concrete mass, which is considered a homogeneous solid. On the other hand, 2-node linear beam elements "B31" of Abaqus and $15 \mathrm{~mm}$ size are used to create the mesh of reinforcement bars with circular cross section whose diameter is equal to that of the corresponding corrugated bars. Moreover, these beam elements interact with the concrete ones as embedded elements.

The mechanical behavior of the concrete brick elements was considered isotropic and a damage-plasticity model of Abaqus was adopted, considering concrete damage both in compression and tension. On the other hand, the mechanical behavior considered for the reinforcement beam elements is both isotropic and elastic-plastic. Mechanical properties of materials were determined according to Model Code 2010 [13] using the tests results summarized in Tables 1 and 2, respectively. Fig. 8 includes the linear and non-linear materials constitutive curves adopted and their damage criteria. Concerning failure mode, the model available in Abaqus is a continuum, plasticitybased, damage model for concrete. It assumes that the main two failure mechanisms are tensile cracking and compressive crushing of the concrete material, considering the complete stress tensor (i.e., six components).

The boundary conditions of the finite element model were elastic supports applied on the nodes of the beam area that are in contact with the elastomeric bearing pads and a pressure load applied on the nodes of the beam area where the test load acts (Fig. 9).

Fig. 10 shows the shear force at the support vs. the vertical displacement at the loaded point, both for the experimental tests and the numerical simulation, showing that even the ultimate load is well captured the numerical response is stiffer than the experimental loaddisplacement relationship. This may be due to early age cracking of the concrete surrounding the longitudinal reinforcement, due to the restrain that steel bars produce to shrinkage and cooling thermal strains during hardening. Such cracks may reduce the beam stiffness, even though the ultimate capacity is not affected. Another possible reason might be the difference between the modulus of elasticity of the actual concrete and that considered in the analysis. It can be seen that the average shear strength of the beam with the higher longitudinal reinforcement $(\rho=0.69 \%)$ is about $6 \%$ higher than that of the beams with the lower longitudinal reinforcement $(\rho=0.54 \%)$. This is consistent with the fact that the longitudinal reinforcement affects basically, the concrete contribution $V_{c u}$, which can be considered proportional to $\rho^{1 / 3}$ approximately: the increment of $V_{c u}$ will be $(0.0069 /$ $0.0054)^{1 / 3}=1.088$.

Fig. 11 shows the experimental and numerically obtained crack patterns for the $\mathrm{M}$ and $\mathrm{H}$ tested beams, showing a very good agreement. In both cases, once the crack crosses de beam web, it continues to progress along the flange-web interface, until the crack propagates inclined inside the flange towards the load application point. This is due to the fact that the normal stress is equal in two adjacent points one in the top of the web and the other in the bottom of the flange, while the shear stress is much lower in the flange. Then an increase of load is needed to obtain the necessary principal stress in the flange, so the crack propagates inside it. Meanwhile the crack develops in the interface due to the transverse tensile stresses at that joint produced by the shear lag.

The strains at the reinforcement were also measured by means of strain gauges glued to three stirrups and two longitudinal bars, as indicated in Fig. 12. The numerical and experimental strains at the stirrups and longitudinal bars are compared in Figs. 13 and 14, respectively. Despite the difficulties existing to experimentally capture the stirrups strains due to local effects of cracking and bond slip, a similar tendency can be observed between the experimental and the numerical results. It is remarkable to notice that both experimental and numerical results show the shear force at which the stirrups are activated, usually associated to the concrete contribution $V_{c}$, prior to concrete cracking.

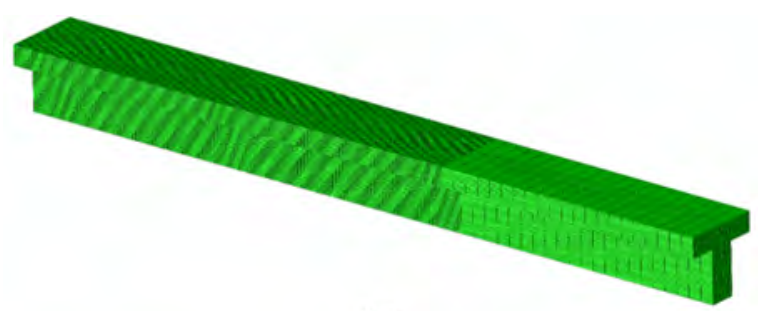

(a)

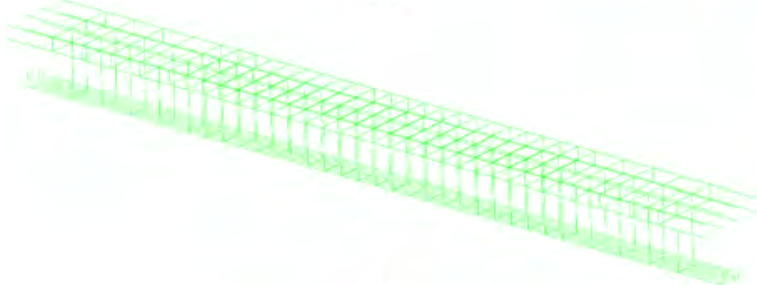

(b)

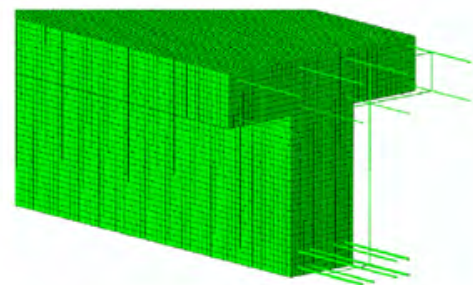

(c)

Fig. 7. FE model of the reinforced concrete beam: (a) solid elements; (b) beam elements; (c) mesh detail. 


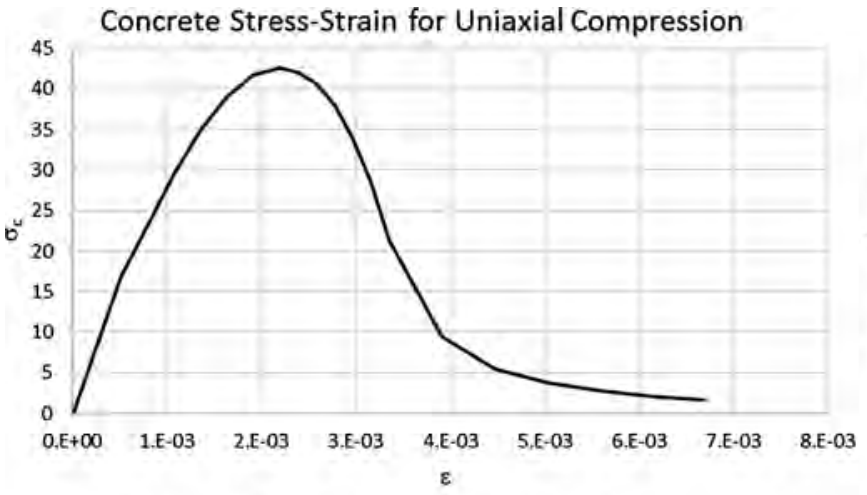

Concrete Stress-Strain for Uniaxial Tension

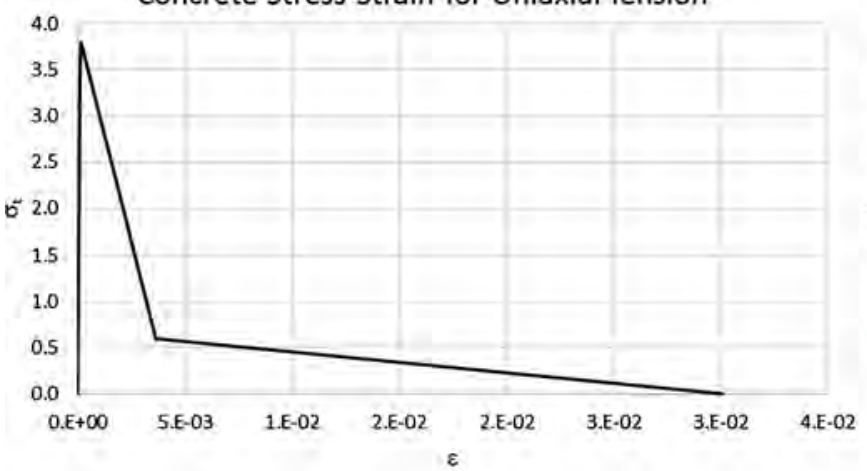

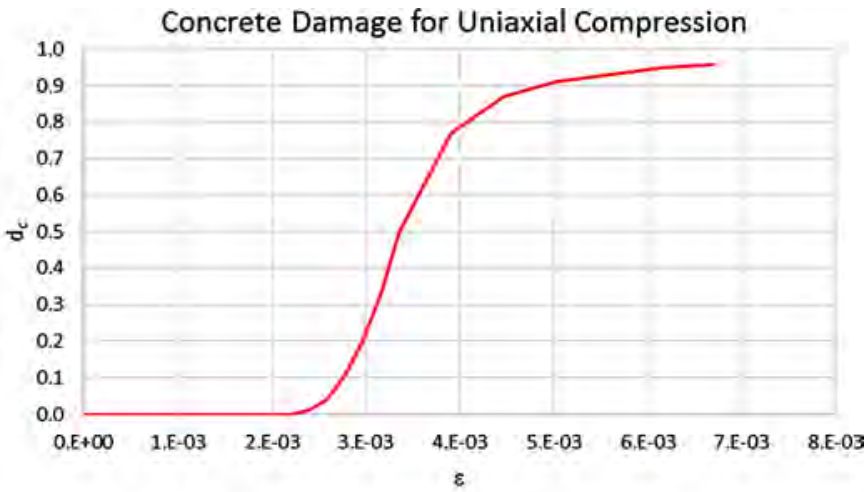

Concrete Damage for Uniaxial Tension

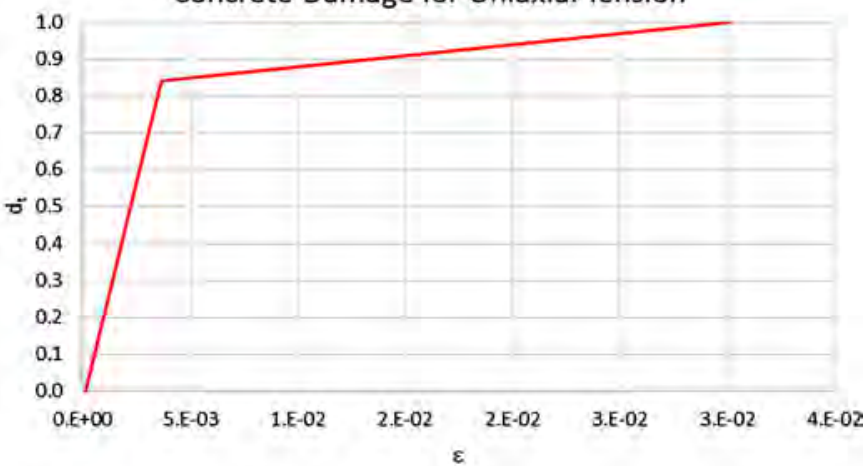

Reinforcement Stress-Strain for Uniaxial Tension/Compression

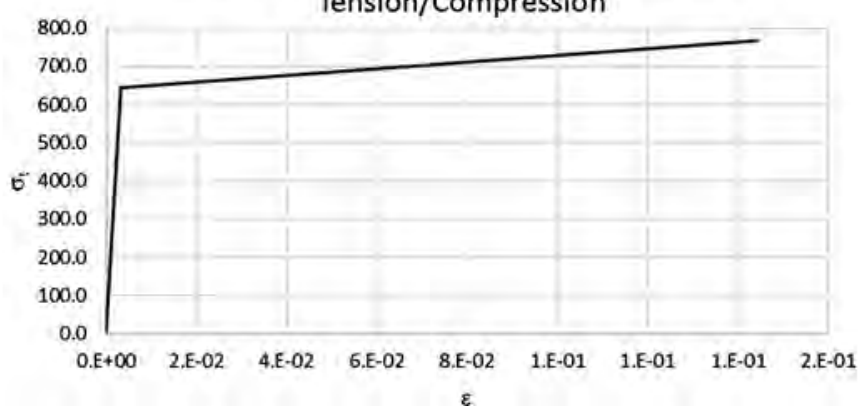

Fig. 8. Mechanical properties of materials.

For both beams, $\mathrm{M}$ and $\mathrm{H}$, the numerical activation of the stirrups takes place for a higher shear force than in the experimental test, what is also probably due to the early age cracking and by the tensile stresses produced in the concrete cover, that consume part of the tensile strength of concrete. Such tensile stresses are due to the non-linear distributions of shrinkage and thermal strains, between the inner and outer fibers of the section, due to the different moisture and environmental conditions.

The differences in the reinforcement strains may be also due to the randomness in the crack development, so that the strain measured at different bar positions, may vary considerably depending on whether the considered measurement device is crossed or not by a crack. Therefore, the comparison between the experimental and numerical results should be better made in terms of the average strains measured along a bar (longitudinal or stirrup) crossed by a crack.

Despite the quantitative differences found in the reinforcement strains, which may be attributed to the above mentioned local effects, the predicted and observed crack patterns and ultimate loads are quite similar. Therefore, it can be considered that the model is reliable

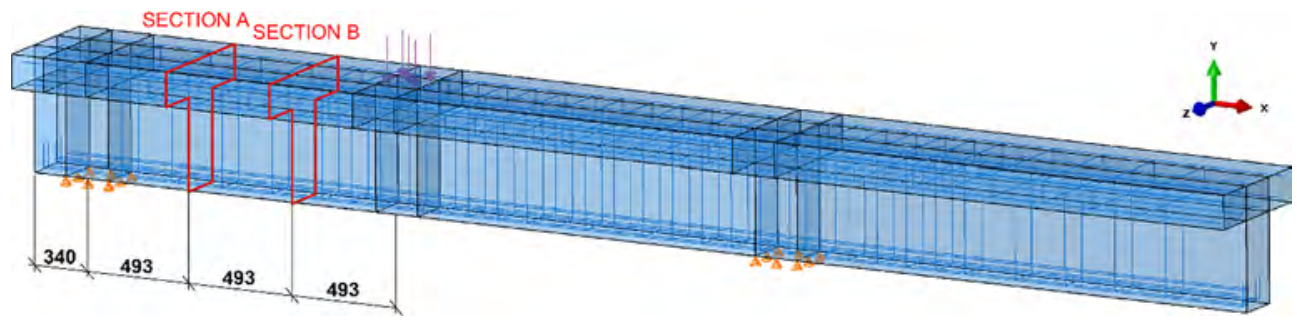

Fig. 9. Boundary conditions and reference sections of the finite element model. 


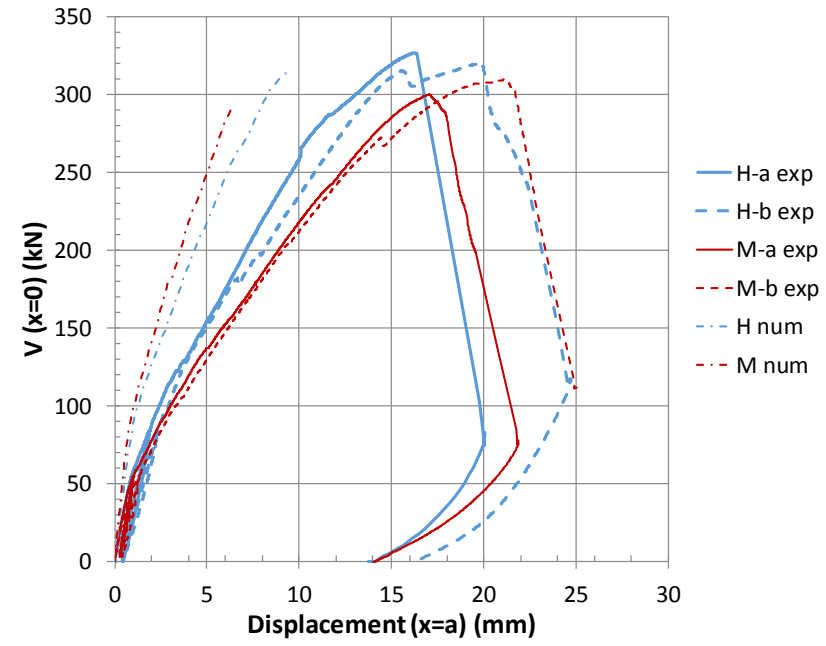

Fig. 10. Shear force at the support vs. displacement under the load application point.

enough to be used as a virtual laboratory to simulate shear tests on beams with other geometrical or reinforcement characteristics, and perform parametric studies.

In Fig. 14, a good correlation is observed between the experimental
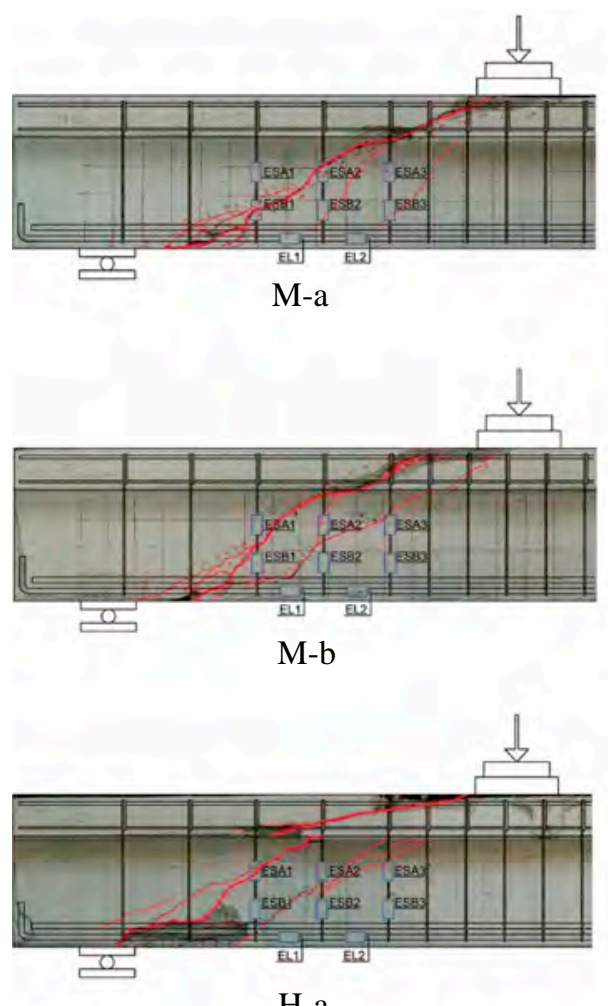

$\mathrm{H}-\mathrm{a}$

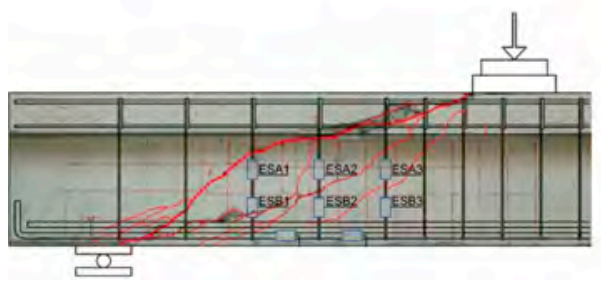

H-b

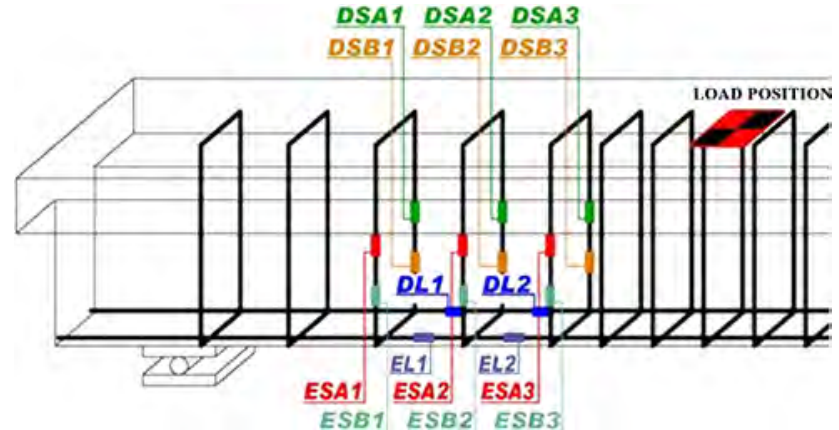

Fig. 12. Position of the strain gauges glued to longitudinal and transverse reinforcement.

and numerical strains at the longitudinal rebars, especially for beam $\mathrm{H}$.

\section{Results}

In order to quantify the contribution of the flanges to the shear strength of beams with T-shaped cross section, the structural response of a number of such type of beams has been studied under increasing the load up to shear failure using the already calibrated numerical model. All beams had the same length, load position and reinforcements than those tested (M- beams, reinforced with two layers of
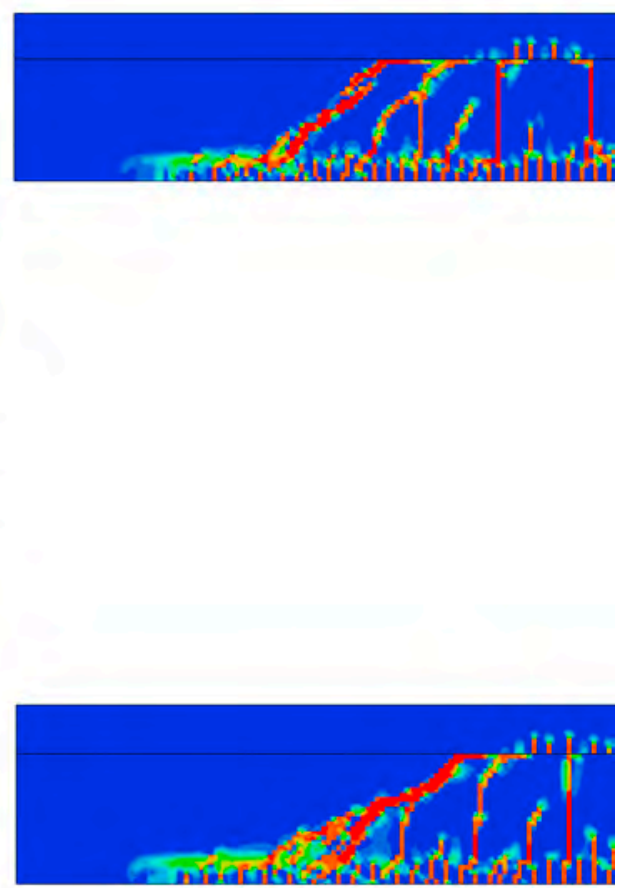

Fig. 11. Comparison of crack patterns between experiments and FE simulations. 

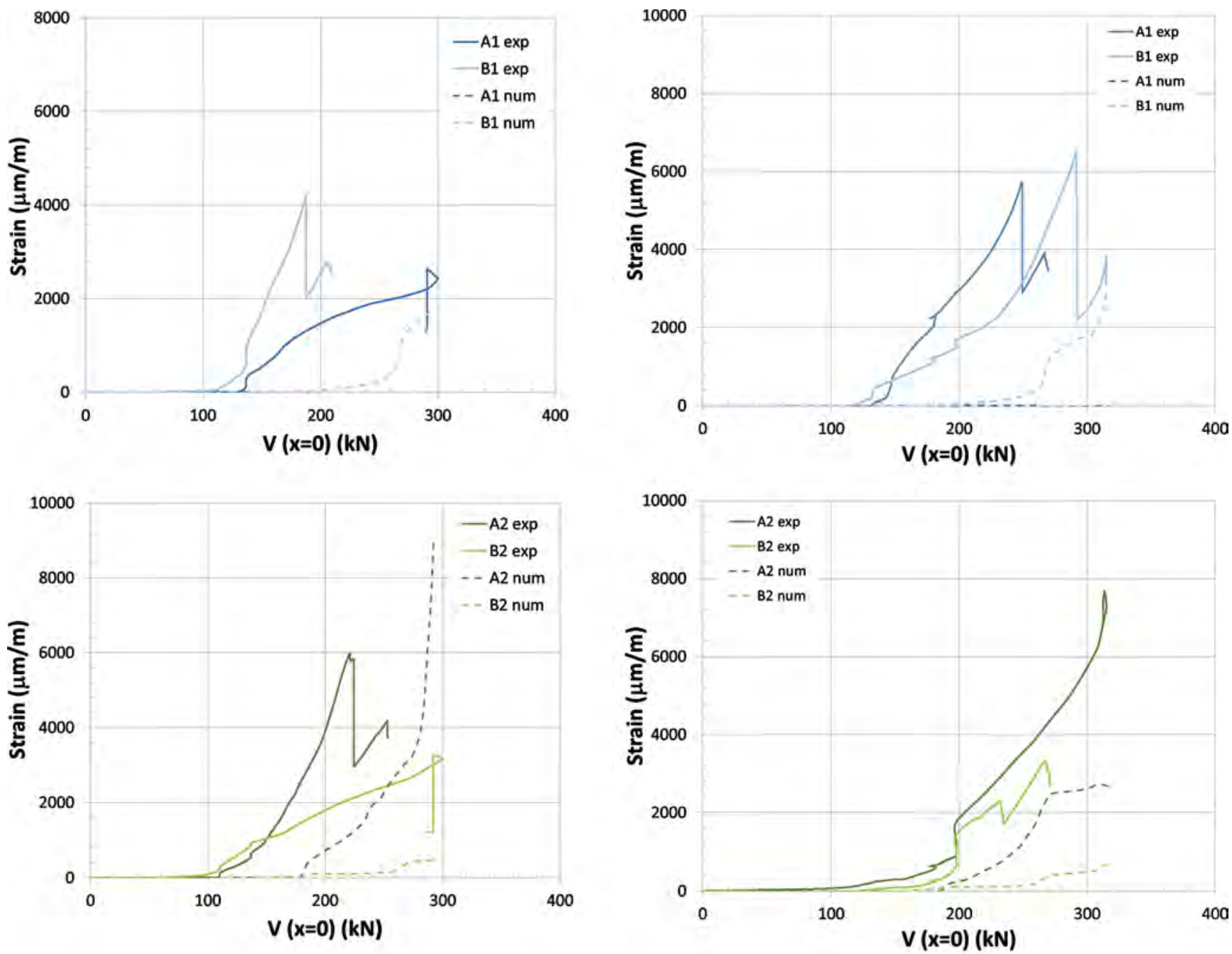

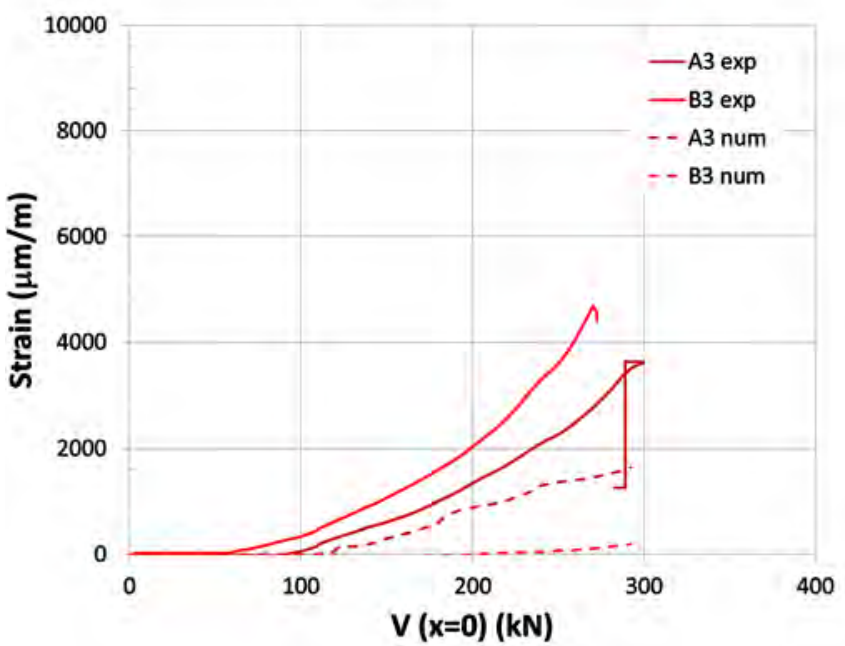

(a)

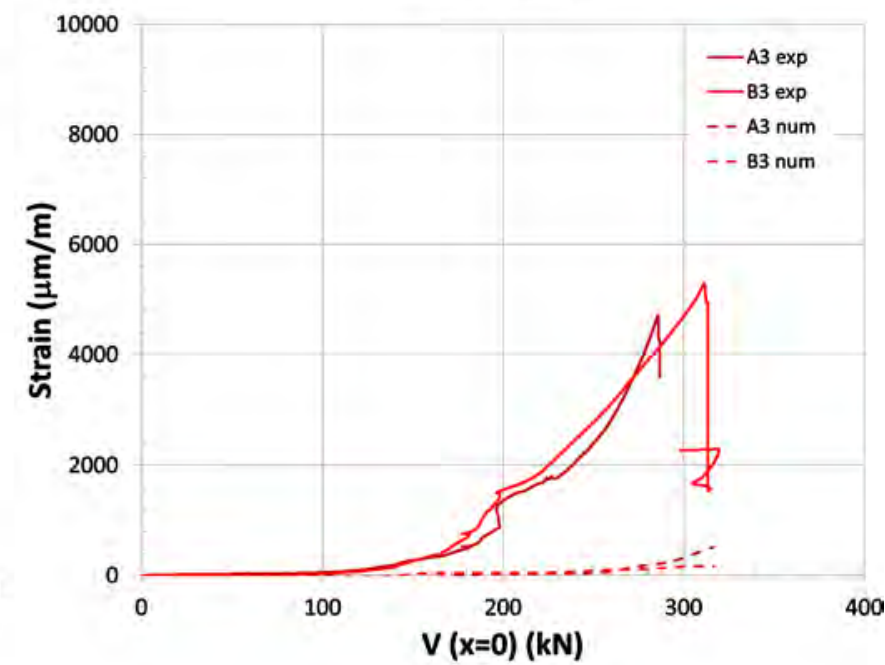

(b)

Fig. 13. Comparison of strains at the stirrups under increasing load: (a) Beam M-A; (b) Beam H-B.

$4 \phi 16$ each and $\mathrm{H}$ beams, reinforced with two layers of $2 \phi 16$ and $2 \phi 20$, each), but with different flanges width and thickness. The flanges width at each side of the web considered, for a constant flange depth of $150 \mathrm{~mm}$, are $0 \mathrm{~mm}$ (rectangular section), $50 \mathrm{~mm}, 100 \mathrm{~mm}, 150 \mathrm{~mm}$, $200 \mathrm{~mm}$ and $300 \mathrm{~mm}$. The flanges depth considered, for a constant width of $200 \mathrm{~mm}$, are 0 (rectangular section), $50 \mathrm{~mm}, 100 \mathrm{~mm}, 150 \mathrm{~mm}$ (actually tested beam) and $200 \mathrm{~mm}$. Fig. 15 shows the geometry of cross section of the analyzed beams.

Figs. 16 and 17 show the vertical shear stresses obtained with the numerical model, just before reaching the failure load, for beams $\mathrm{M}$ and $H$, respectively with $h_{f}=150 \mathrm{~mm}$, at section B (see Fig. 9), where the concrete strut lies in the flanges. Results for sections with $b_{f}=300$ and 


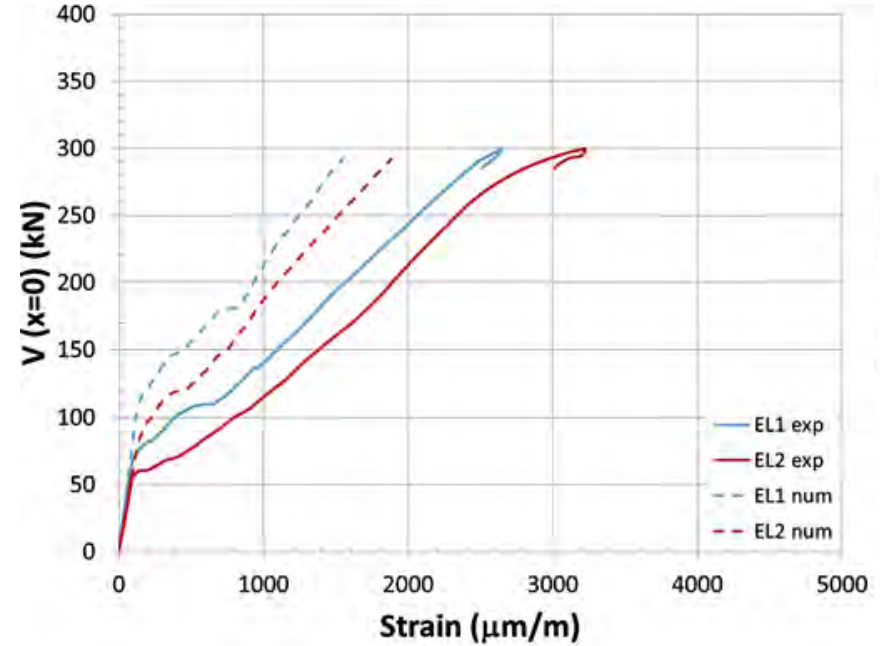

(a)

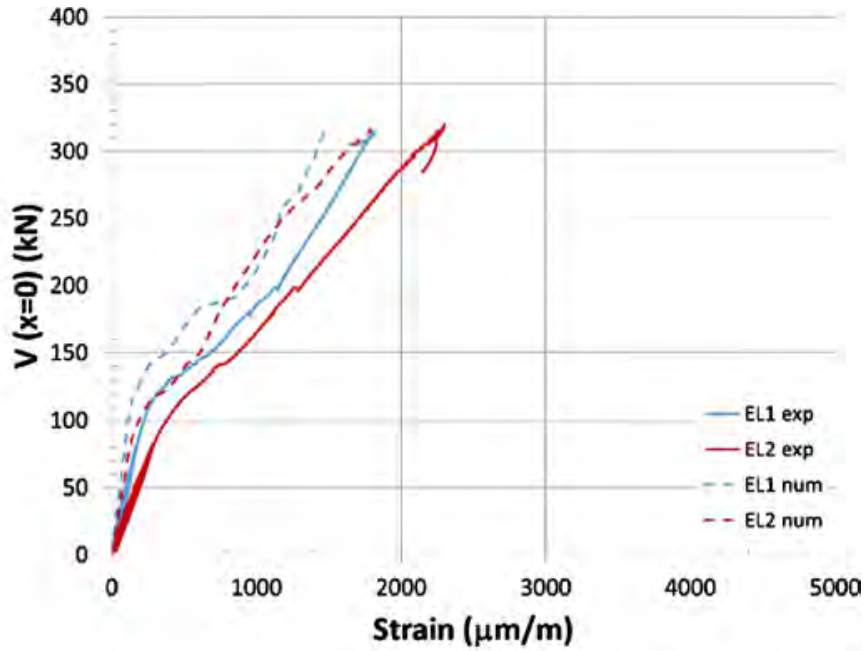

(b)

Fig. 14. Comparison of strains at the longitudinal reinforcement, under increasing load: (a) Beam M-A; (b) Beam H-B.
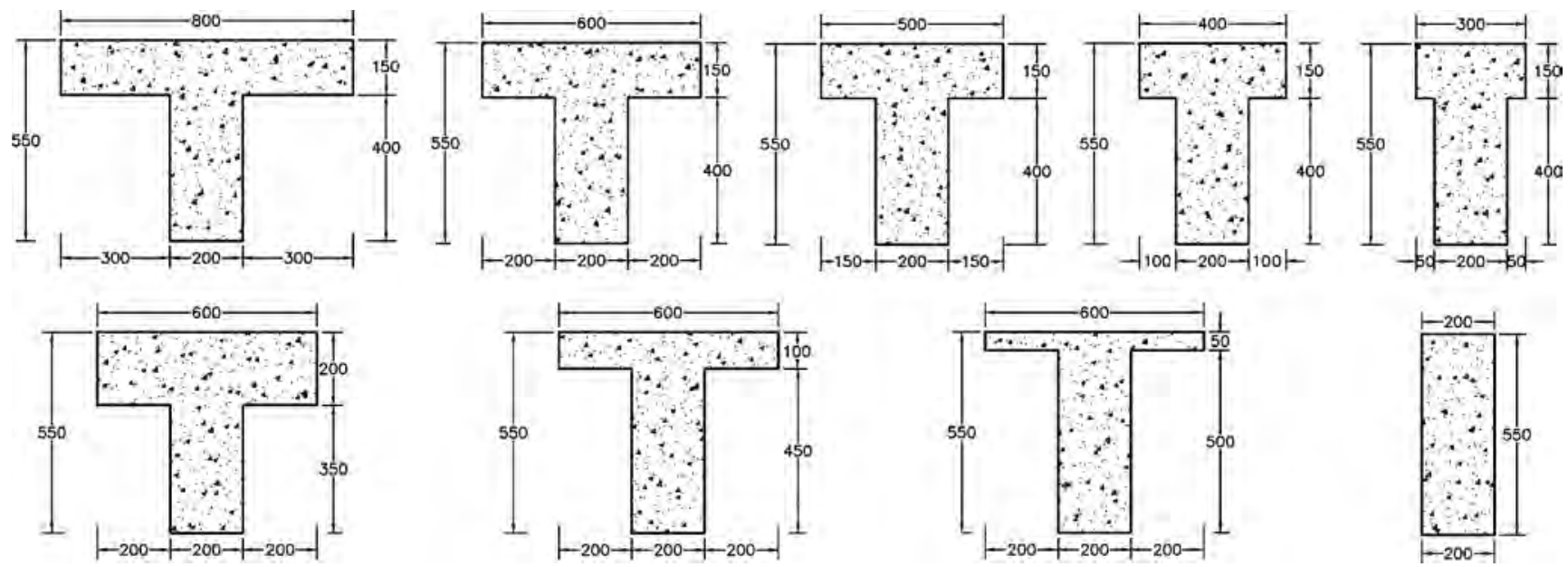

Fig. 15. Cross sections geometry of the analyzed beams.

$b_{\mathrm{f}}=500 \mathrm{~mm}$ are not included in these figures due to space limitations, although the contribution of the flanges and web to the shear strength can be found in Tables 3-6.

Figs. 18 and 19 show the shear stresses of beams $\mathrm{M}$ and $\mathrm{H}$, for constant width $b_{f}=600 \mathrm{~mm}$ and different thickness for the flange.

It can be observed, especially in the sections with wider flanges, that shear stresses are located not only in the web but also in the flanges. In addition, almost no qualitative differences are found between beams $\mathrm{M}$ and $\mathrm{H}$. It is also remarkable that the thicker is the flange, the more shear stresses are placed on it. Tables 3-6 show the total shear force resisted as well as the percentage of shear force resisted by the whole web, by the part of the web inside the head, by the flanges at both parts of the web and by the whole head, for sections A and B, beams M and $\mathrm{H}$. In this context, the head means the flanges plus the portion of web between them. Such values have been obtained by integrating the vertical shear stresses provided by the numerical model at each considered region.

The following relevant aspects can be observed:

- The shear carried by the flanges in section A is lower than in section $\mathrm{B}$, because section A crosses the lower part of the compression strut. The lower distance from section A to the support reaction does not allow the compression stresses to be fully transferred from the web to the compression head. For this reason, only the results at B section will be analyzed next.

- For a constant thickness and variable flange width, the percentage of shear carried by the flanges is higher for beam $\mathrm{M}$, with a lower longitudinal reinforcement ratio, because the crack width is higher, the neutral axis depth is smaller and the shear stresses tend to concentrate in the un-cracked compression head more than in beam $\mathrm{H}$. However, this difference tends to disappear in the case of constant width after a certain thickness, because a non-negligible part of the shear stresses which are placed under the neutral axis lie also in the flanges.

- The percentage of shear carried by the flanges increases as the flange width increases, even though there is an asymptotic tendency towards a $20 \%$ in beam $\mathrm{H}$ and $25 \%$ in beam M. These results coincide with those previously obtained experimentally and summarized in [23].

- The percentage of shear carried by the flanges notably increases as the flange thickness increases, however no asymptotic tendency is observed in this case, because a relevant part of the shear stresses which are placed under the neutral axis lie also in the flanges.

- The maximum percentage of shear taken by the flanges for the studied cases, corresponding to a section with $h_{f}=200 \mathrm{~mm}$ and $b_{f}=600 \mathrm{~mm}$, and it is $31.3 \%$ for the lower reinforcement $(M)$, which can be considered as a highly significant value.

- The maximum shear force taken by the whole head reaches $51.8 \%$ at 

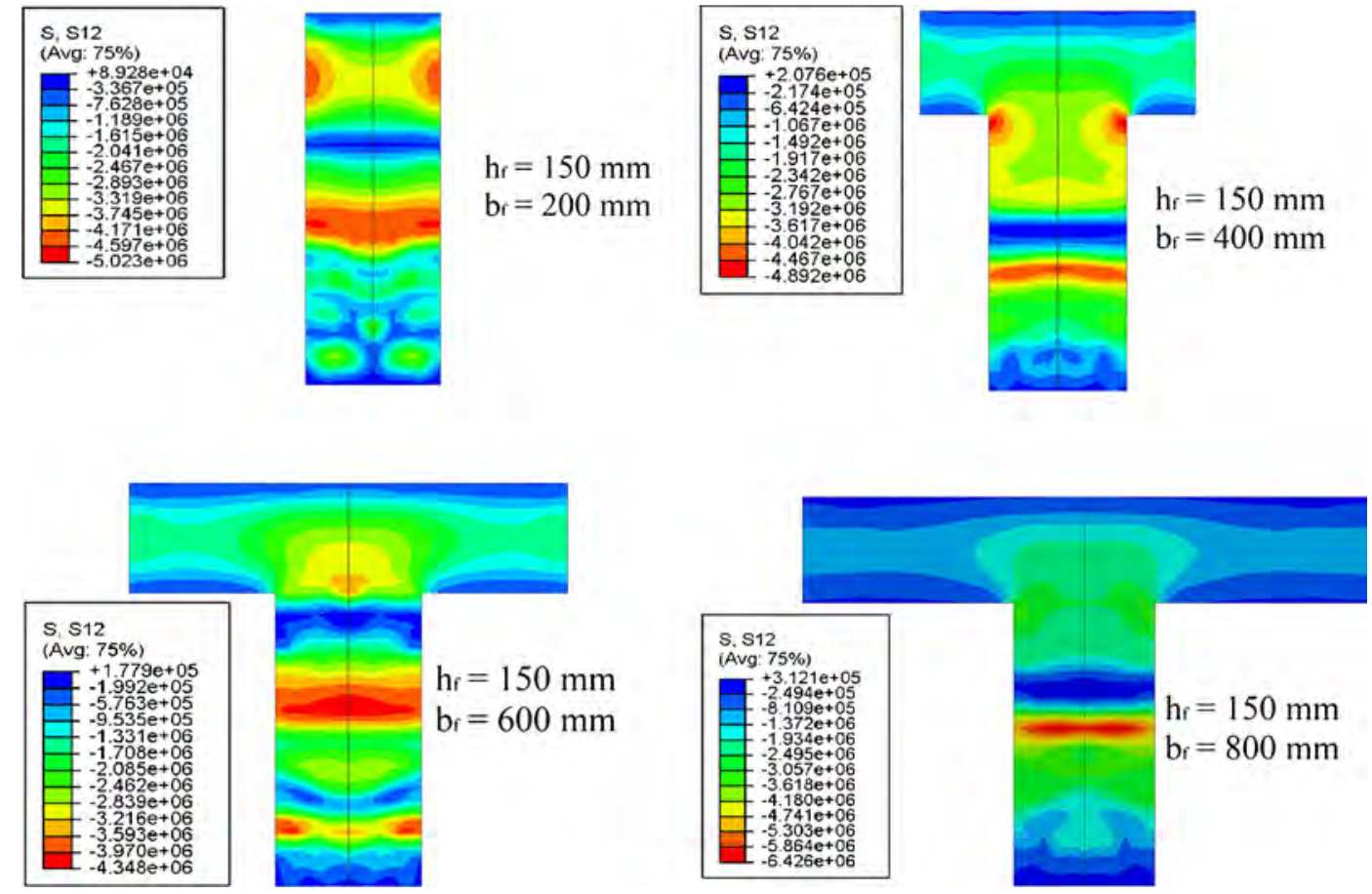

Fig. 16. Vertical shear stresses obtained with the numerical model at beam $M$, Section $B$, with $h_{f}=150 \mathrm{~mm}$ and different flange widths.
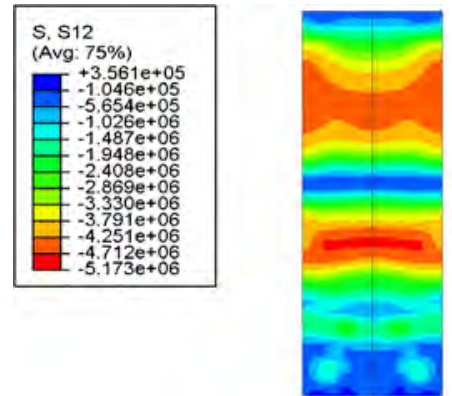

$\mathrm{h}_{\mathrm{r}}=150 \mathrm{~mm}$
$\mathrm{~b}_{\mathrm{f}}=200 \mathrm{~mm}$
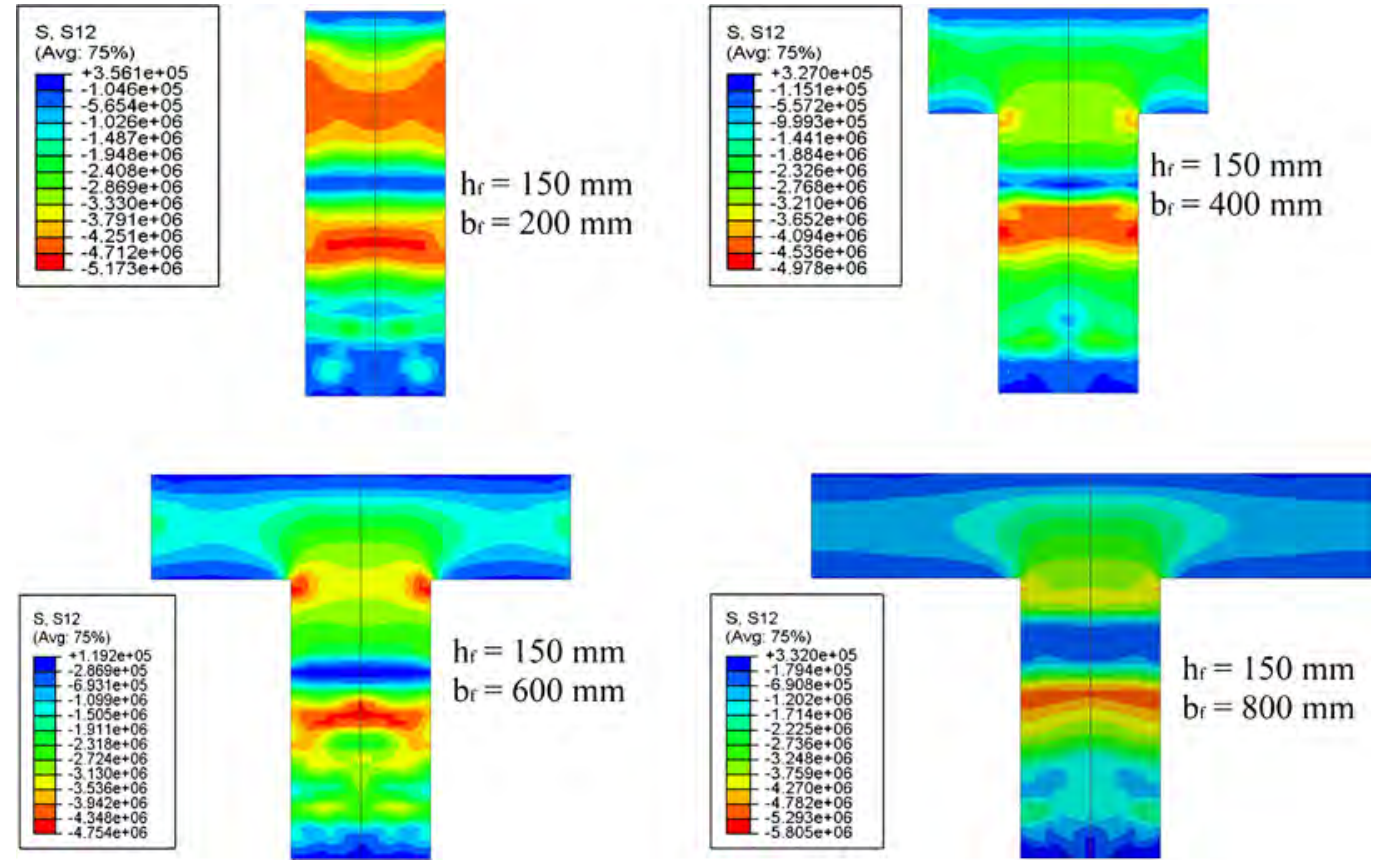

Fig. 17. Vertical shear stresses obtained with the numerical model at beam $H$, Section $B$, with $h_{f}=150 \mathrm{~mm}$ and different flange widths.

Table 3

Contribution to shear strength of the web and flanges in $\mathrm{H}$ beam for $\mathrm{h}_{\mathrm{f}}=150 \mathrm{~mm}$ and different flange widths.

\begin{tabular}{|c|c|c|c|c|c|c|c|c|c|c|c|c|}
\hline \multirow{2}{*}{$\begin{array}{l}\text { Reinforcement type } \\
\text { Beam sections }\end{array}$} & \multicolumn{12}{|c|}{ Beam H. $h_{f}=150 \mathrm{~mm}$} \\
\hline & $\mathrm{A}$ & & & & & & B & & & & & \\
\hline Flange width (mm) & 200 & 300 & 400 & 500 & 600 & 800 & 200 & 300 & 400 & 500 & 600 & 800 \\
\hline Shear force $V_{y}(k N)$ & 287 & 288 & 290 & 293 & 317 & 320 & 287 & 288 & 290 & 293 & 317 & 320 \\
\hline$\% \mathrm{~V}_{\mathrm{y}}$ Total Web & 100.0 & 78.5 & 87.3 & 88.0 & 85.8 & 85.3 & 100.0 & 74.3 & 62.8 & 59.4 & 60.9 & 55.7 \\
\hline$\%$ Head - Flanges & 0.0 & 4.7 & 2.9 & 2.7 & 3.6 & 4.1 & 0.0 & 8.0 & 15.7 & 18.1 & 19.2 & 23.5 \\
\hline$\%$ Head - Web & & 16.8 & 9.8 & 9.3 & 10.6 & 10.6 & & 20.7 & 21.5 & 22.5 & 19.9 & 20.8 \\
\hline$\%$ Total Head & & 21.5 & 12.7 & 12.0 & 14.2 & 14.7 & & 28.7 & 37.2 & 40.6 & 39.1 & 44.3 \\
\hline
\end{tabular}


Table 4

Contribution to shear strength of the web and flanges in $M$ beam for $h_{f}=150 \mathrm{~mm}$ and different flange widths.

\begin{tabular}{|c|c|c|c|c|c|c|c|c|c|c|}
\hline \multirow{2}{*}{$\begin{array}{l}\text { Reinforcement type } \\
\text { Beam sections }\end{array}$} & \multicolumn{10}{|c|}{ Beam M. $h_{f}=150 \mathrm{~mm}$} \\
\hline & A & & & & & B & & & & \\
\hline Flange width (mm) & 200 & 300 & 400 & 500 & 600 & 200 & 300 & 400 & 500 & 600 \\
\hline Shear force Vy $(\mathrm{kN})$ & 260 & 264 & 271 & 282 & 292 & 260 & 264 & 271 & 282 & 292 \\
\hline$\%$ Vy Total Web & 100.0 & 87.3 & 86.8 & 88.4 & 85.9 & 100 & 76.5 & 67.6 & 58.8 & 53.1 \\
\hline$\%$ Head-Flanges & 0.0 & 2.7 & 3.1 & 2.0 & 3.5 & 0.0 & 7.2 & 12.4 & 21.2 & 23.3 \\
\hline \% Head-web & & 10.1 & 10.1 & 9.6 & 10.6 & & 16.3 & 20.0 & 20.0 & 23.6 \\
\hline$\%$ Total Head & & 12.8 & 13.2 & 11.6 & 14.1 & & 23.5 & 32.4 & 41.2 & 46.9 \\
\hline
\end{tabular}

Table 5

Contribution to shear strength of web and flanges in $\mathrm{H}$ beam for $\mathrm{b}_{\mathrm{f}}=600 \mathrm{~mm}$ and different flange thickness.

\begin{tabular}{|c|c|c|c|c|c|c|c|c|c|c|}
\hline \multirow{2}{*}{$\begin{array}{l}\text { Reinforcement type } \\
\text { Beam sections }\end{array}$} & \multicolumn{10}{|c|}{ Beam H. $b_{f}=600 \mathrm{~mm}$} \\
\hline & A & & & & & $\mathrm{B}$ & & & & \\
\hline Flange thickness (mm) & 0 & 50 & 100 & 150 & 200 & 0 & 50 & 100 & 150 & 200 \\
\hline Shear force Vy $(\mathrm{kN})$ & 287 & 290 & 294 & 317 & 319 & 287 & 290 & 294 & 317 & 319 \\
\hline$\% \mathrm{~V}_{\mathrm{y}}$ Total Web & 100.0 & 97.4 & 88.3 & 85.8 & 66.8 & 100.0 & 95.8 & 84.6 & 60.9 & 50.8 \\
\hline$\%$ Head-Flanges & 0.0 & 0.3 & 2.3 & 3.6 & 12.4 & 0.0 & 0.4 & 5.4 & 19.2 & 30.3 \\
\hline$\%$ Head-web & & 2.3 & 9.4 & 10.6 & 20.8 & & 3.8 & 10.0 & 19.9 & 18.9 \\
\hline$\%$ Total Head & & 2.6 & 11.7 & 14.2 & 33.2 & & 4.2 & 15.4 & 39.1 & 49.2 \\
\hline
\end{tabular}

Table 6

Contribution to shear strength of web and flanges in $M$ beam for $b_{f}=600 \mathrm{~mm}$ and different flange thickness.

\begin{tabular}{|c|c|c|c|c|c|c|c|c|c|c|}
\hline \multirow{2}{*}{$\begin{array}{l}\text { Reinforcement type } \\
\text { Beam sections }\end{array}$} & \multicolumn{10}{|c|}{ Beam M. $b_{f}=600 \mathrm{~mm}$} \\
\hline & A & & & & & B & & & & \\
\hline Flange thickness (mm) & 0 & 50 & 100 & 150 & 200 & 0 & 50 & 100 & 150 & 200 \\
\hline Shear force $V_{y}(k N)$ & 260 & 267 & 270 & 292 & 293 & 260 & 267 & 270 & 292 & 293 \\
\hline$\% \mathrm{~V}_{\mathrm{y}}$ Total Web & 100.0 & 97.7 & 94.1 & 85.9 & 76.5 & 100.0 & 95.1 & 75.9 & 53.1 & 48.2 \\
\hline$\%$ Head-Flanges & 0.0 & 0.3 & 0.8 & 3.5 & 9.1 & 0.0 & 0.6 & 9.8 & 23.3 & 31.3 \\
\hline$\%$ Head-web & & 2.0 & 5.1 & 10.6 & 14.4 & & 4.3 & 14.3 & 23.6 & 20.5 \\
\hline \% Total Head & & 2.3 & 5.9 & 14.1 & 23.5 & & 4.9 & 24.1 & 46.9 & 51.8 \\
\hline
\end{tabular}

section $\mathrm{B}$ in beam $\mathrm{M}$, what confirms the hypothesis that an important part of the shear force is taken by the compression concrete head.
In addition, it has been observed that the horizontal path along the flange-web interface increases as the flange thickness increases (Fig. 20). The reason for this behavior is that the sudden change in the
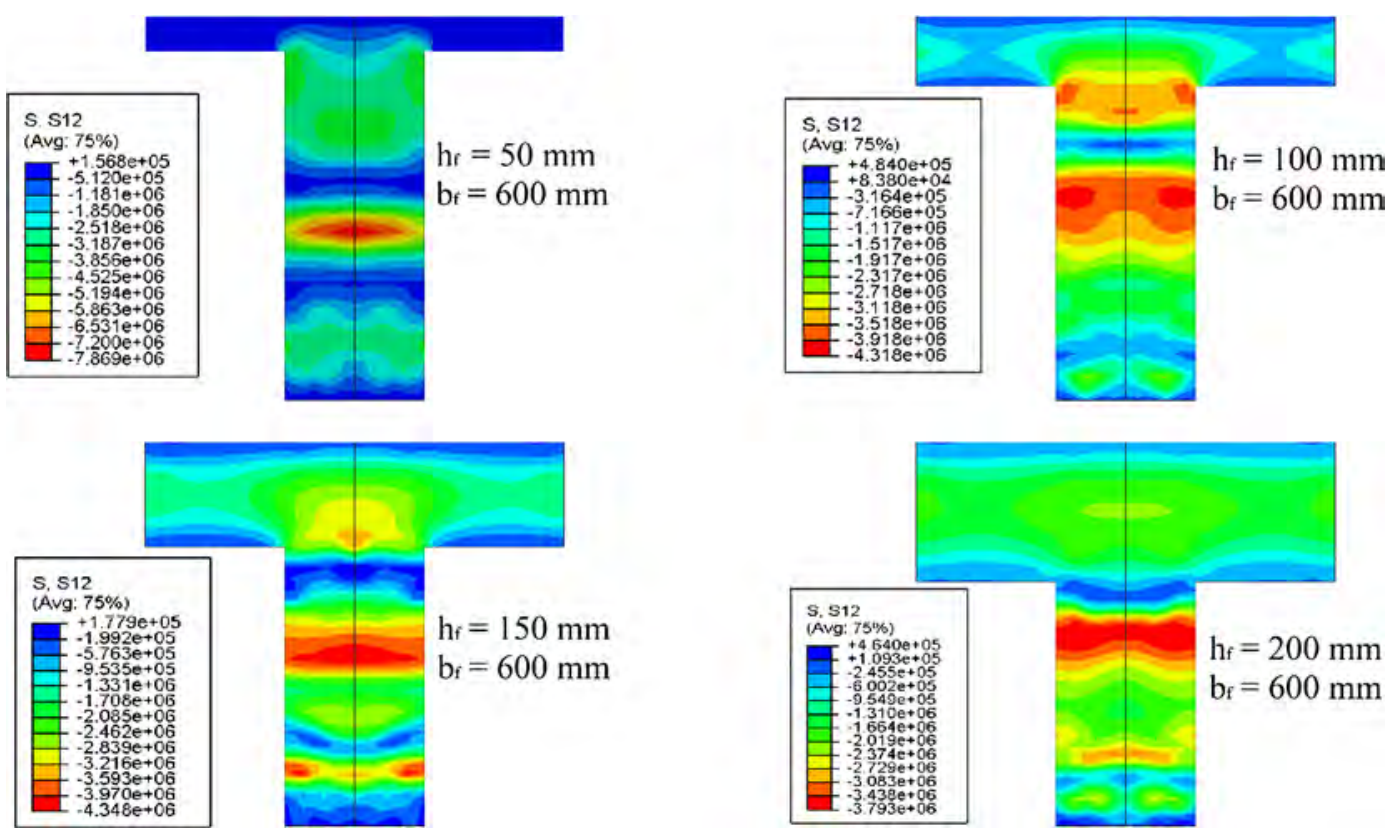

Fig. 18. Shear stresses at beam $M$, Section $B$, with $b_{f}=600 \mathrm{~mm}$ and variable flange thickness. 

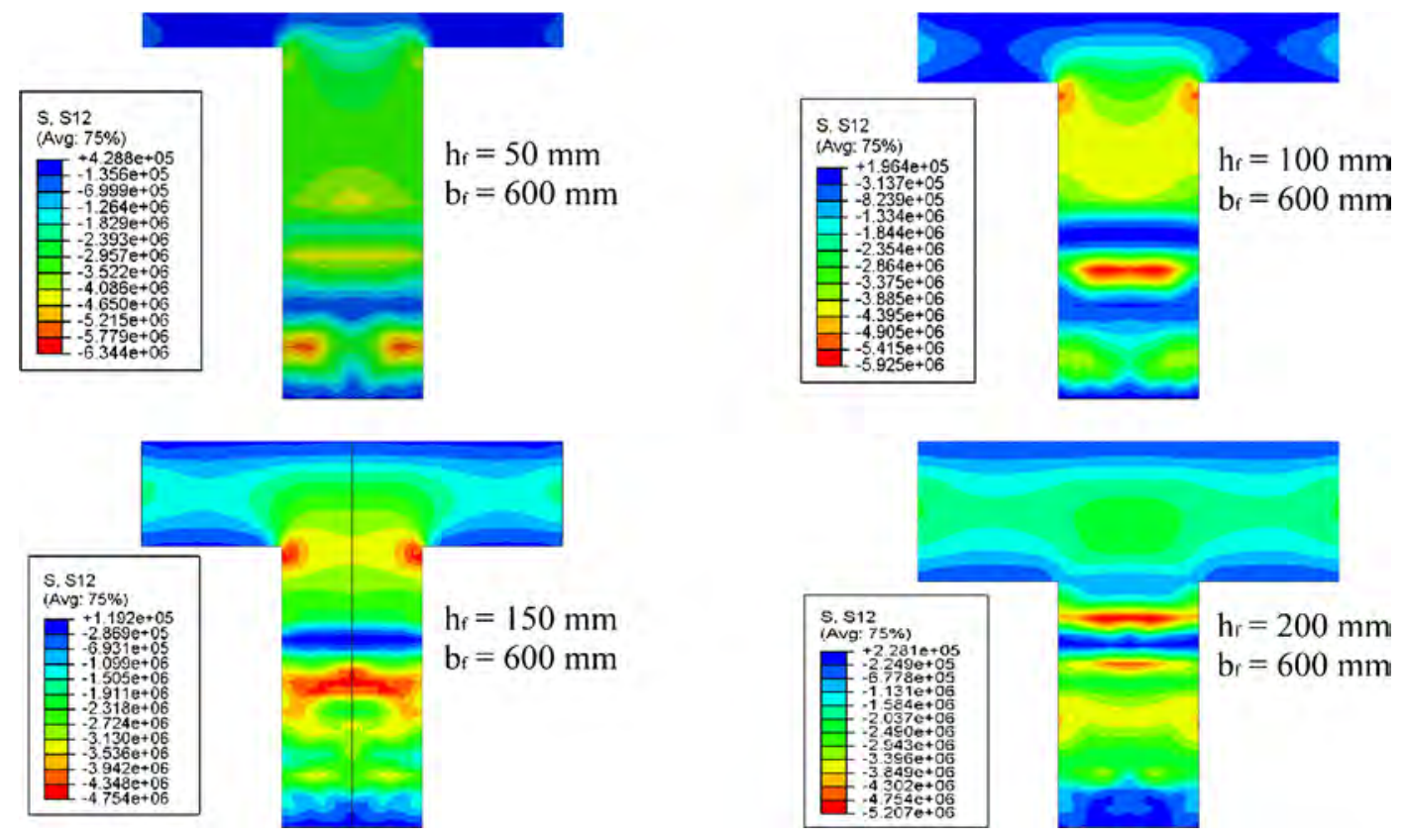

Fig. 19. Shear stresses at beam $H$, Section $B$, with $b_{f}=600 \mathrm{~mm}$ and variable flange thickness.

Type $\mathrm{M}$ beam

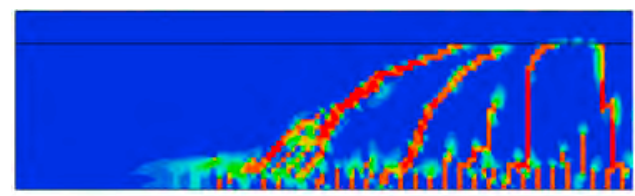

Flange thickness $100 \mathrm{~mm}$

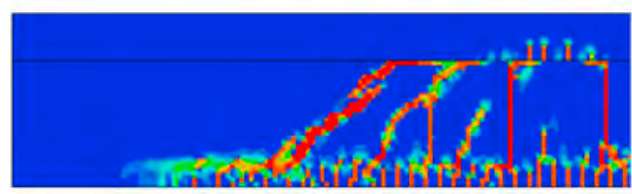

Flange thickness $150 \mathrm{~mm}$

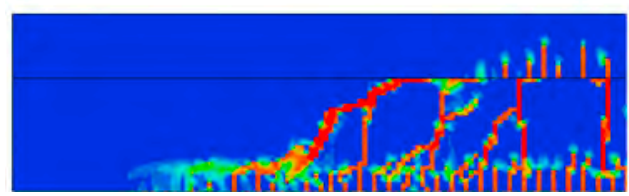

Flange thickness $200 \mathrm{~mm}$
Type H beam

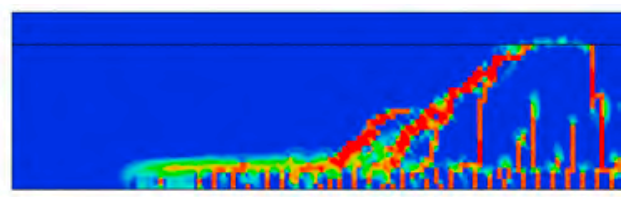

Flange thickness $100 \mathrm{~mm}$

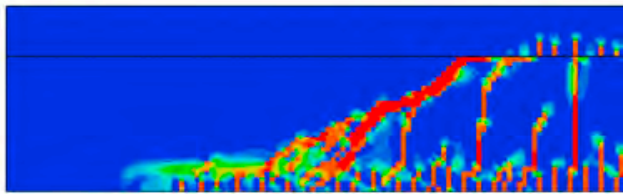

Flange thickness $150 \mathrm{~mm}$

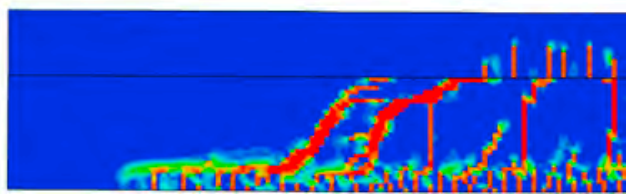

Flange thickness $200 \mathrm{~mm}$

Fig. 20. Comparison of crack patterns for different flange thickness.

section width, from the web to the head, requires a considerable increment of shear stresses in order the crack to enter into the flanges, and meanwhile such value is reached, the critical shear crack propagates along the flanges-web horizontal joint. Since the shear stresses are lower in the section with higher moment of inertia, a higher shear force will be necessary to produce a principal tensile stress big enough to propagate the crack inside the concrete head. Therefore, a longer horizontal crack will be produced in the section with thicker flanges.

\section{Conclusions}

The following conclusions can be drawn from the experimental and numerical analyses performed:

(1) The capacity of the 3D nonlinear Finite Element structural analysis model developed to accurately reproduce the experimental response of beams with T-shaped sections subjected to shear tests has been demonstrated. The only relevant differences found are the strains at the stirrups, which are affected by the localization of the critical crack, whose position is not coincident in the tests and in the numerical simulations.

(2) Simulations of shear tests on $\mathrm{T}$ beams with different flanges dimensions and reinforcement amounts have been performed. It has been confirmed that, at failure, the shear stresses tend to 
concentrate around the neutral axis in the compressed concrete zone in flexure, thus resulting a non-negligible contribution of the flanges to the shear strength. The maximum percentage of shear force taken by the whole compressed concrete zone in flexure reaches $51.8 \%$, while the maximum percentage of shear taken by the flanges for the studied cases, is $31.3 \%$, which can be considered as a highly significant value.

(3) It has been found that the part of shear force taken by the flanges depends on the position of the section considered along the beam, resulting higher for sections where the compression stresses are fully transferred from the web to the compression head.

(4) The amount of longitudinal reinforcement affects the percentage of shear force carried by the flanges. The lower reinforcement ratio, the wider is the critical crack, thus reducing its shear transfer capacity in the web and increasing the shear resisted by the flanges.

(5) The shear force carried by the flanges increases as their width and depth increase. Since shear stresses concentrate around the web, their extension in the flanges is limited, so their contribution shows an asymptotic tendency towards a $25 \%$ of the total shear resisted. This tendency is not observed as the flanges depth increases.

The obtained results indicate that a shear effective flange width may be obtained as a function of the flange dimensions and longitudinal reinforcement ratio. In addition, other parameters, such as the amount of transverse reinforcement in the web and in the flanges, may have a relevant role due to the concrete confinement provided by them on the concrete. For these reasons, the influence of these and other geometric parameters, such as ratios $b_{f} / b_{w}, h_{f} / b_{f}$ and $h_{f} / h$ will be studied in future works, with the purpose of deriving a simple but accurate expression for the effective shear flanges width.

\section{Competing interest}

None.

\section{Acknowledgements}

The authors wish to acknowledge the financial support of The Ministry of Economy and Competitiveness of the Government of Spain (MINECO) for providing funds for projects BIA2015-64672-C4-1-R and the European Regional Development Funds (ERDF). The financial support of Infrastructures de Catalunya (ICAT) is also highly appreciated.

\section{Appendix A. Supplementary material}

Supplementary data to this article can be found online at https:// doi.org/10.1016/j.engstruct.2019.03.057.

\section{References}

[1] Vecchio FJ, Collins MP. The modified compression-field theory for reinforced concrete elements subjected to shear. ACI J 1986;83(2):219-31.

[2] Hsu T. Softened truss model theory for shear and torsion. ACI Struct J 1988;85(6):624-35.

[3] Reineck KH. Ultimate shear force of structural concrete members without transverse reinforcement derived from a mechanical model. ACI Struct J (SP-885) 1991;88(5):592-602.

[4] Zararis PD, Papadakis GC. Diagonal shear failure and size effect in RC beams without web reinforcement. J Struct Eng 2001;127(7):733-42. https://doi.org/10.1061/(ASCE)07339445(2001).

[5] Tureyen AK, Frosch RJ. Concrete shear strength: another perspective. ACI Struct J 2003;100(5):609-15.

[6] Choi KK, Park HG, Wight JK. Unified shear strength model for reinforced concrete beams part I: development. ACI St. J 1 2007;104(2):142-52.

[7] Bažant ZP, Yu Q, Gerstle W, Hanson J, Ju JW. Justification of ACI 446 proposal for updating ACI code provisions for shear design of reinforced concrete beams. Struct J 2007;104:601-10.

[8] Collins MP, Bentz EC, Sherwood EG, Xie L. An adequate theory for the shear strength of reinforced concrete structures. Mag Concr Res 2008;60(9):635-50. https://doi.org/10. $1680 /$ macr.2008.60.9.635.

[9] Muttoni A, Ruiz MF. Shear strength of members without transverse reinforcement as function of critical shear crack width. ACI Struct J 2008;105(2):163-72.

[10] Park HG, Kang S, Choi KK. Analytical model for shear strength of ordinary and prestressed concrete beams. Eng Struct 2013;46:94-103. https://doi.org/10.1016/j.engstruct.2012. 07.015 .

[11] Marí A, Bairán J, Cladera A, Oller E, Ribas C. Shear-flexural strength mechanical model for the design and assessment of reinforced concrete beams. Struct Infrastruct Eng 2015;11:1399-419. https://doi.org/10.1080/15732479.2014.964735.

[12] CEN European Committee for Standardization. Eurocode 2: design of concrete structures: part 1: general rules and rules for buildings. Brussels. CEN; 2002

[13] FIB - International Federation for Structural Concrete. FIB Model Code for Concrete Structures 2010. Berlin: Verlag Ernst \& Sohn; 2013. http://doi.org/10.1002/ 9783433604090

[14] ACI-Committee-318. Building code requirements for structural concrete and commentary. USA: ACI; 2008. ISBN 978-0-87031-264-9.

[15] Ferguson PM, Thompson JN. Diagonal tension in t-bemas without stirrups. ACI J Proc 1953;49(3):665-75.

[16] Leonhardt F. Shear and torsion in prestressed concrete. London: Fédération Internationale de la Précontrainte, Cement \&Concrete Association; 1970.

[17] Kani MW, Huggins MW, Kani G, Wittkopp RR. Kani on shear in reinforced concrete. Toronto, Canada: University of Toronto, Dept. of Civil Engineering; 1979. ISBN $0772770018,9780772770011$.

[18] Placas A, Regan PE, Baker ALL. Shear failure of reinforced concrete beams. J Amer Concr Inst 1971;68:763-73.

[19] Giaccio C, Al-Mahaidi R, Taplin G. Experimental study on the effect of flange geometry on the shear strength of reinforced concrete T-beams subjected to concentrated loads. Can J Civ Eng 2002;29:911-8. https://doi.org/10.1139/102-099.

[20] Ribas C, Cladera A. Experimental study on shear strength of beam-and-block floors. Eng Struct 2013;57:428-42. https://doi.org/10.1016/j.engstruct.2013.10.001.

[21] Pujol M, Oller E, Marí A. Contribution of external transverse strengthening with FRP laminates to the shear strength of $\mathrm{T}$ beams (in Spanish). Proceedings VI congress of the spanish concrete association (ACHE), Madrid, 3-5 June 2014. 2014.

[22] Pujol M. Refuerzo a cortante de estructuras de ormgión armado con laminados de polímeros reforzados con fibras (FRP). Verificación experimental $\mathrm{PhD}$ Thesis Universitat Politècnica de Catalunya; 2018.

[23] ACI-ASCE Committee 426. The shear strength of reinforced concrete members. ACI J Proc 1973;70:1091-187.

[24] Swamy RN, Qureshi SA. An ultimate shear strength theory for reinforced concrete Tbeams without web reinforcement. Matér Constr 1974;7:181-9. https://doi.org/10.1007/ BF02473833.

[25] Moayer H, Regan P. Shear strength of prestressed and reinforced concrete T-beams. ACI Spec Publ 1974;42(1):183-221.

[26] Kotsovos MD, Bobrowski J, Eibl J. Behaviour of reinforced concrete T-beams in shear. Struct Eng Part B R\&D Q 1987;65B:1-10.

[27] Hoang CL. Shear strength of non-shear reinforced concrete elements: Part 1-Statically indeterminate beams. Research Report, Department of Structural Engineering and Materials. Lyngby, Denmark: Technical University of Denmark; 1997.

[28] Zararis IP, Karaveziroglou MK, Zararis PD. Shear strength of reinforced concrete T-beams. ACI Struct J 2006;103:693-700.

[29] Bairán JM, Marí AR. Coupled model for the non-linear analysis of anisotropic sections subjected to general 3D loading. Part 1: theoretical formulation. Comput Struct 2006;84(31-32):2254-63. https://doi.org/10.1016/j.compstruc. 2006.08.036.

[30] Wolf TS, Frosch RJ. Shear design of prestressed concrete: a unified approach. J Struct Eng 2007;133:1512-9. https://doi.org/10.1061/(ASCE)0733-9445(2007) 133:11(1512).

[31] Ribas C, Cladera A. Mechanical model for calculating the shear strength of beam-and block floors. Informes de la Construcción 2014;66(1):1-10.

[32] Celada U. Analysis of reinforced concrete T sections subjected to shear and bending, constructed in phases Master Thesis Barcelona, Spain: Department of Construction Engineering, Polytechnic University of Catalonia; 2013

[33] Cladera A, Marí A, Ribas C, Bairán J, Oller E. Predicting the shear-flexural strength of slender reinforced concrete T and I shaped beams. Eng Struct 2015;101:386-98. https:// doi.org/10.1016/j.engstruct.2015.07.025.

[34] Li YA, Hsu TTC, Hwang SJ. Shear strength of prestressed and non-prestressed concrete beams. Concrete International, American Concrete Institute; 2017. p. 53-7.

[35] Navarro-Gregori J, Miguel-Sosa P, Fernández-Prada MA, Filippou FC. A 3D numerical model for reinforced and prestressed concrete elements subjected to combined axial, bending, shear and torsion loading. Eng Struct 2007;29(12):3404-19. https://doi.org/10. 1016/j.engstruct.2007.09.001.

[36] Belletti B, Damoni C, Hendriks MAN, Den Uijl JA. Non-linear finite element analyses of existing reinforced concrete bridge beams. IABSE Symposium Report, vol. 99 no. 7. 2013. p. $1631-8$.

[37] Hawileh R, Abdalla JA, Tanarslan M. Modeling of nonlinear response of R/C shear deficient T-beam subjected to cyclic loading. Comput Concr 2012;10(4):413-28. https:// doi.org/10.12989/cac.2012.10.4.419.

[38] Dassault Systèmes. Abaqus software [accessed 28 June 2018]. https://www.3ds.com/ products-services/simulia/products/abaqus/; 2018.

[39] Government of Spain, Ministerio de Fomento. Instrucción del Hormigón Estructural (Structural Concrete Code) EHE-08, Madrid, España. 